\title{
CARACTERÍSTICAS DE LA FORMACIÓN DEPORTIVA \\ DE LOS PARTICIPANTES EN LOS IV JUEGOS ESCOLARES \\ CENTROAMERICANOS Y DEL CARIBE, ARMENIA 2013
}

\author{
CHARACTERISTICS OF PARTICIPANTS' SPORTS TRAINING IN IV JUEGOS ESCOLARES \\ CENTROAMERICANOS Y DEL CARIBE, ARMENIA 2013
}

\author{
Adriana María Agudelo . $^{1}$ \\ Carlos Federico Ayala Z. ${ }^{2}$ \\ Santiago Ramos B. ${ }^{3}$ \\ Angélica María García G. ${ }^{4}$ \\ Luis Gerardo Melo ${ }^{5}$ \\ Héctor Haney Aguirre-Loaiza ${ }^{6}$ \\ Luisa Fernanda Gutiérrez A. $^{7}$ \\ Hernando Alejandro Martínez ${ }^{8}$ \\ Kelly Marcela Ovalle Martínez ${ }^{9}$
}

\section{RESUMEN}

Objetivo: Caracterizar la formación deportiva de participantes en los IV Juegos Deportivos Escolares Centroamericanos y del Caribe, Armenia, 2013. Materiales y métodos: Estudio cuantitativo, prospectivo, con alcance descriptivo y de corte transversal. De un universo de 683 participantes, fue seleccionada intencionalmente una muestra no probabilística de 233 deportistas (102 hombres y 131 mujeres), entre 15 y 17 años de edad, pertenecientes a nueve delegaciones participantes, quienes respondieron una encuesta que indagaba sobre la formación deportiva. Resultados: Los deportistas encuestados afirman que la organización del deporte en la escuela se da en clubes deportivos, los deportistas pertenecen a entidades deportivas independientes a su institución educativa y dichas entidades no poseen convenios con las instituciones educativas; el promedio de edad de inicio es 9,57 años, en entidades deportivas independientes de su institución; al 52,3 \% de los deportistas se les realizaron pruebas para identificar talento; y de ellas las más utilizadas fueron las pruebas físicas. Dentro del control se encuentra que el 89,2 \% realizó pruebas permanentemente y las más utilizadas son las físicas, se identifica que los deportistas tienen un bagaje en competencias internacionales y un promedio de 7 competencias por año; finalmente, se establece que el principal agente motivador son los padres.

Palabras claves: deporte escolar; formación deportiva; entrenamiento juvenil

1 Magíster en Educación. Licenciada en Educación Física, Recreación y Deporte. Docente magisterio Alcaldía de Manizales. Grupo Cumanday Actividad Física y Deporte. Correo electrónico: adrimagugi@gmail.com

2 Doctor en Motricidad Humana. Magíster en Educación, especialista en Entrenamiento Deportivo. Docente Universidad de Caldas. Grupo Cumanday Actividad Física y Deporte. Correo electrónico: federico.ayala@ucaldas.edu.co

3 Magíster en Metodología del Entrenamiento Deportivo. Docente Universidad de Caldas. Grupo Cumanday Actividad Física y Deporte. Correo electrónico: santiago.ramos@ucaldas.edu.co

4 Magíster y especialista en Intervención Integral en el Deportista. Docente Universidad de Caldas. Grupo Cumanday Actividad Física y Deporte. Correo electrónico: angelica.garcia@ucaldas.edu.co

5 Doctor en Entrenamiento Deportivo. Docente Universidad de Caldas. Grupo Cumanday Actividad Física y Deporte. Correo electrónico: luis.melo@ ucaldas.edu.co

6 Licenciado en Educación Física, Recreación y Deporte. Psicólogo. Estudiante de Maestría en Psicología. Docente Universidad del Valle. Universidad del Quindío. Grupo Cumanday Actividad Física y Deporte. Correo electrónico: hector.aguirre@correounivalle.edu.co

7 Licenciado en Educación Física, Recreación y Deporte. Docente Politécnico Grancolombiano. Grupo Cumanday Actividad Física y Deporte. Correo electrónico: lufegu23@hotmail.com

8 Magíster en Educación. Licenciado en Educación Física, Recreación. Docente Universidad del Quindío. Grupo Tejiendo Redes. Correo electrónico: hamartinez@uniquindio.edu.co

9 Licenciado en Educación Física, Recreación y Deporte. Entrenadora Club deportivo Asociación Servicios y Soluciones de Colombia, assc. Correo electrónico: Kellymartinez88@hotmail.com 


\section{Abstract}

Aim: To characterize the sports formation of participants at the IV Juegos Deportivos Escolares Centroamericanos y del Caribe, Armenia, 2013. Materials and methods: quantitative, prospective, descriptive scope and cross-sectional study. From a total of 683 participants, it was intentionally selected a nonprobabilistic sample of 233 athletes (102 men and 131 women) between 15 and 17 years old, from nine delegations, who responded to a survey about sports training. Results: athletes surveyed said that the organization of sports in schools occur in sports clubs, athletes belong to sports entities that are not related to their schools and those entities do not have agreements with their educational institutions; the average age of onset is 9,57 years, independent sporting bodies of the institution; 52,3 $\%$ of the athletes underwent tests to identify talent and those were the most commonly used physical evidence. Within the control group it was found that $89,2 \%$ take tests permanently and the most commonly conducted are the physical ones, it was identified that athletes have a background in international competitions and an average of 7 competitions per year. Finally, it is stated that the principal motivational agent is the parents' sport.

Keywords: school sport; sports training; youth training

Fecha de recepción: 23 de octubre de 2015

Fecha de aprobación: 7 de marzo de 2016

Para citar este artículo:

Agudelo, A.M., Ayala, C.F., Ramos, S., García, A.M., Melo, L.G., Aguirre-Loaiza, H.H., Gutiérrez, L.F., Martínez, H.A. y Ovalle, K.M. (2016). Características de la formación deportiva de los participantes en IV Juegos Escolares Centroamericanos y del Caribe, Armenia 2013. Lúdica Pedagógica, (23), 127-139.

\section{INTRODUCCIÓN}

La formación deportiva se conoce como el ámbito donde pueden integrarse diferentes aspectos, que van desde la formación en principios pedagógicos y sociales hasta la agrupación de jóvenes deportistas que se perfilan hacia el alto rendimiento (Blázquez, 1999; Murcia, Taborda y Ángel 2003; Pérez-Turpin y Suarez, 2007), aunque la formación deportiva carece de una definición específica, debido a que se debe tener en cuenta el tipo de proceso, ya sea desde el deporte orientado dentro del currículo escolar hasta la escuela de formación deportiva, los cuales tienen diferentes características y requerimientos específicos según el interés de desarrollo, el tipo de participación y los roles que se deben asumir para el proceso (Vásquez et al., 2001).

La enseñanza del deporte no se debe basar solamente en la selección y especialización temprana, el excesivo componente de competencias ofrecidas, la búsqueda de resultados a corto plazo (Pérez-Turpín y Suárez, 2007), los cuales corresponden al modelo de alto rendimiento, que, a su vez, es considerado como no adecuado para los procesos de iniciación deportiva con carácter educativo; el autor propone ciertas características que complementan los modelos contemporáneos de preparación deportiva, por ejemplo, definir objetivos globales para una educación más integral, utilizar metodologías activas que involucren todo el acervo motor y cognitivo del alumno deportista, incluir valores educativos en la enseñanza y el aprendizaje, y desarrollar propuestas competitivas adaptadas a la iniciación deportiva.

En el proceso de formación deportiva, también es importante tener en cuenta el entorno vital, ya que este contiene las condiciones básicas de vida del deportista, su estabilidad emocional, el reconocimiento social y sus perspectivas de futuro, al igual que el entorno del entrenamiento como el apoyo técnico, científico, tecnológico, de infraestructura y de dedicación prioritaria (Capetillo, 2011; Sáenz-López, 2010). Por consiguiente, es base para que en la preparación se desenvuelva el desarrollo físico, técnico-táctico, intelectual, psíquico y moral, con el objetivo central de alcanzar logros o el máximo rendimiento, lo cual hace que sea un proceso 
complejo por sus acciones, además de la sistematización de lo que conlleva la formación del deportista (Gómez, 2011; Melo, Moreno, Aguirre, 2012; Weineck, 2005).

Por otra parte, Blázquez (1999) indica que la iniciación y formación deportiva es esencialmente un proceso que involucra la socialización, la integración, lo educativo y formativo hacia la adquisición de capacidades, habilidades, destrezas, conocimientos y actitudes, que permitan la inclusión y la participación activa de todos los participantes, a través del involucramiento de la dirigencia deportiva y burocrática (política) en el apoyo ininterrumpido a los procesos de iniciación y formación deportiva, lo cual ofrecerá las semillas de deportistas para el alto rendimiento (Ramos y Taborda, 2001).

Para desarrollar adecuadamente los procesos de formación deportiva, se deben evaluar constantemente, teniendo en cuenta elementos como la cantidad de deportistas qué iniciaron y continúan el proceso, los logros obtenidos, las inversiones y apoyos de todo tipo (económicos, recursos materiales, logísticos y humanos, entre otros), la progresión del deportista en diferentes áreas y la preparación y formación de los entrenadores (Acosta, 2012). Lo cual lleva a que se piense primero en el proceso desde la planificación, el alcance del logro y el mantener este, no solamente en el resultado final.

La formación del deportista hacia el rendimiento competitivo se refiere a procesos que involucran conceptos, aspectos, estrategias, factores, propiedades, objetivos y acciones que son orientadas para la consecución de altos logros, metas y/o rendimientos deportivos, por lo cual, se precisan diferentes etapas de planeación, en las cuales se debe tener en cuenta una organización a partir de estrategias deportivas, un plan de acción, y, específicamente, una preparación que busque poner a punto los medios del entorno vital y del entrenamiento, en concordancia con la preparación de las competencias y elaboración de las tácticas a corto, mediano y largo plazo (García, Navarro, y Ruíz, 1996; Gómez, 2011; Issurin, 2012).

La preparación deportiva ha tenido diferentes modelos teóricos, Blázquez (1999) ha propuesto fases como las de entrenamiento básico, formación motora general, formación deportiva de base, especialización y perfeccionamiento deportivo. Por su parte, Platonov (1999) considera la preparación inicial, preparación preliminar de base, preparación especial de base, etapa de realización de máximos resultados y de conservación de los máximos resultados.

La literatura hasta el momento ha ofrecido amplias reflexiones y propuestas teóricas que plantean posibles procesos de la formación, desde perspectivas más específicas a otras cuyas posiciones son más holísticas (Fraile et al., 2004; Fernández, Vila, y Rodríguez, 2004; Giménez, Abad, y Robles, 2010; González, García, Contreras y Sánchez-Mora; 2009; Hernández, 2000; Hoyos, 2012; Leiva, 2010; Sáenz-López, 2010; Ramos y Taborda, 2001; Tabernero, Márquez, y Llanos, 2001).

Teniendo en cuenta que la formación deportiva se puede referir tanto al ámbito educativo como al deporte orientado a la competencia de alto nivel, hasta ahora no se ha logrado conocer las características de la formación deportiva en un contexto regional; en consecuencia, uno de los principales retos de los profesionales del área es contrastar las propuestas teóricas con los procesos reales. Así las cosas, un primer intento para resolver el problema que se pone de manifiesto en el presente estudio es la caracterización de los procesos de formación, y cuyo resultados permitirán implicaciones para la toma de decisiones de los diversos actores del deporte escolar. En este sentido, el objetivo de la presente investigación fue estudiar las características de formación deportiva (sociodemográficas, organizacionales de la institución educativa, agentes socializadores, procesos de iniciación deportiva, pruebas para selección de talentos y competencias) en los deportistas participantes en los IV Juegos Deportivos Escolares Centroamericanos y del Caribe, Armenia-Colombia, 2013.

\section{METODOLOGÍA}

Se realizó un estudio cuantitativo, prospectivo, con alcance descriptivo, de corte transversal. La población objeto fueron los deportistas participantes en los IV Juegos Deportivos Escolares Centroamericanos y del Caribe, Armenia 2013, con un aproximado de 684 deportistas de 10 delegaciones participantes. La muestra no probabilística estuvo integrada por 233 deportistas entre 15 y 17 años de edad, de nueve delegaciones a las que se pudo tener acceso. La técnica de recolección de información fue una encuesta para deportistas, que indagaba sobre las características de los procesos de formación deportiva: iniciación, organización deportiva 
escolar, pruebas para establecer talento, pruebas de control, agentes motivadores y participación deportiva. La encuesta elaborada por el grupo investigador fue sometida al criterio de expertos nacionales en el área de entrenamiento deportivo y aplicada en los escenarios deportivos, a la salida de los mismos, después de las competencias y lugares de alojamiento. Con el programa SPSS v. 20 fueron calculadas medidas de tendencia central (media) y dispersión (desviación típica), así como análisis de frecuencia. Los evaluados firmaron un consentimiento informado, a la luz de la Declaración de Helsinki y la Resolución 8430.

\section{RESULTADOS Y DISCUSIÓN}

\section{Características sociales y demográficas}

Los resultados concernientes al perfil sociodemográfico de los deportistas escolares se describen en la tabla 1.

Tabla 1. Frecuencia y porcentajes de características sociodemográficas según delegación (país)

\begin{tabular}{|c|c|c|c|c|c|c|c|c|c|c|c|}
\hline \multirow{2}{*}{ Variable } & & \multicolumn{9}{|c|}{ Delegación (país) } & \multirow{2}{*}{ Total } \\
\hline & & COL & CTR & DOM & GUA & MÉX & NIC & PAN & PUR & VEN & \\
\hline \multicolumn{12}{|l|}{ Genero } \\
\hline Masculino & $\begin{array}{l}\mathrm{n} \\
\%\end{array}$ & $\begin{array}{l}27 \\
11,6\end{array}$ & $\begin{array}{l}2 \\
0,8\end{array}$ & $\begin{array}{l}6 \\
2,5\end{array}$ & $\begin{array}{l}8 \\
3,4\end{array}$ & $\begin{array}{l}6 \\
2,5\end{array}$ & $\begin{array}{l}2 \\
0,8\end{array}$ & $\begin{array}{l}8 \\
3,4\end{array}$ & $\begin{array}{l}13 \\
5,5\end{array}$ & $\begin{array}{l}30 \\
12,8\end{array}$ & $\begin{array}{l}102 \\
43,7\end{array}$ \\
\hline Femenino & $\begin{array}{l}\mathrm{n} \\
\%\end{array}$ & $\begin{array}{l}35 \\
15,0\end{array}$ & $\begin{array}{l}3 \\
1,2\end{array}$ & $\begin{array}{l}11 \\
4,7\end{array}$ & $\begin{array}{l}19 \\
8,1\end{array}$ & $\begin{array}{l}2 \\
0,8\end{array}$ & $\begin{array}{l}3 \\
1,2\end{array}$ & $\begin{array}{l}10 \\
4,2\end{array}$ & $\begin{array}{l}24 \\
10,3\end{array}$ & $\begin{array}{l}24 \\
10,3\end{array}$ & $\begin{array}{l}131 \\
56,2\end{array}$ \\
\hline \multicolumn{12}{|c|}{ Zona de residencia } \\
\hline Rural & $\begin{array}{l}\mathrm{n} \\
\% \\
\end{array}$ & $\begin{array}{l}3 \\
1,3 \\
\end{array}$ & $\begin{array}{l}2 \\
0,8 \\
\end{array}$ & $\begin{array}{l}4 \\
1,7 \\
\end{array}$ & $\begin{array}{l}11 \\
4,7 \\
\end{array}$ & $\begin{array}{l}0 \\
0,0\end{array}$ & $\begin{array}{l}0 \\
0,0\end{array}$ & $\begin{array}{l}4 \\
1,7\end{array}$ & $\begin{array}{l}16 \\
6,9\end{array}$ & $\begin{array}{l}11 \\
4,7\end{array}$ & $\begin{array}{l}51 \\
21,8\end{array}$ \\
\hline Urbano & $\begin{array}{l}\mathrm{n} \\
\%\end{array}$ & $\begin{array}{l}59 \\
25,6\end{array}$ & $\begin{array}{l}3 \\
1,3\end{array}$ & $\begin{array}{l}13 \\
5,6\end{array}$ & $\begin{array}{l}15 \\
6,5\end{array}$ & $\begin{array}{l}8 \\
3,4\end{array}$ & $\begin{array}{l}5 \\
2,1\end{array}$ & $\begin{array}{l}14 \\
6,0\end{array}$ & $\begin{array}{l}20 \\
8,7\end{array}$ & $\begin{array}{l}42 \\
18,0\end{array}$ & $\begin{array}{l}179 \\
76,8\end{array}$ \\
\hline $\mathrm{N} / \mathrm{R}$ & $\begin{array}{l}\mathrm{n} \\
\%\end{array}$ & $\begin{array}{l}0 \\
0,0\end{array}$ & $\begin{array}{l}0 \\
0,0\end{array}$ & $\begin{array}{l}0 \\
0,0\end{array}$ & $\begin{array}{l}1 \\
0,4\end{array}$ & $\begin{array}{l}0 \\
0,0\end{array}$ & $\begin{array}{l}0 \\
0,0\end{array}$ & $\begin{array}{l}0 \\
0,0\end{array}$ & $\begin{array}{l}1 \\
0,4\end{array}$ & $\begin{array}{l}1 \\
0,4\end{array}$ & $\begin{array}{l}3 \\
1,3\end{array}$ \\
\hline \multicolumn{12}{|c|}{ Carácter de la institución } \\
\hline Pública & $\begin{array}{l}\mathrm{n} \\
\% \\
\end{array}$ & $\begin{array}{l}39 \\
16,7\end{array}$ & $\begin{array}{l}4 \\
1,7\end{array}$ & $\begin{array}{l}14 \\
6,0\end{array}$ & $\begin{array}{l}8 \\
3,4\end{array}$ & $\begin{array}{l}6 \\
2,5\end{array}$ & $\begin{array}{l}4 \\
1,7\end{array}$ & $\begin{array}{l}5 \\
2,1\end{array}$ & $\begin{array}{l}24 \\
10,3\end{array}$ & $\begin{array}{l}35 \\
15,0\end{array}$ & $\begin{array}{l}139 \\
59,6\end{array}$ \\
\hline Privada & $\begin{array}{l}\mathrm{n} \\
\%\end{array}$ & $\begin{array}{l}21 \\
9,0\end{array}$ & $\begin{array}{l}1 \\
0,4\end{array}$ & $\begin{array}{l}3 \\
1,2\end{array}$ & $\begin{array}{l}18 \\
7,7\end{array}$ & $\begin{array}{l}2 \\
0,8\end{array}$ & $\begin{array}{l}1 \\
0,4\end{array}$ & $\begin{array}{l}13 \\
5,5\end{array}$ & $\begin{array}{l}13 \\
5,5\end{array}$ & $\begin{array}{l}19 \\
8,1\end{array}$ & $\begin{array}{l}91 \\
39,0\end{array}$ \\
\hline $\mathrm{N} / \mathrm{R}$ & $\begin{array}{l}\mathrm{n} \\
\%\end{array}$ & $\begin{array}{l}2 \\
0,8\end{array}$ & $\begin{array}{l}0 \\
0,0\end{array}$ & $\begin{array}{l}0 \\
0,0\end{array}$ & $\begin{array}{l}1 \\
0,4\end{array}$ & $\begin{array}{l}0 \\
0,0\end{array}$ & $\begin{array}{l}0 \\
0,0\end{array}$ & $\begin{array}{l}0 \\
0,0\end{array}$ & $\begin{array}{l}0 \\
0,0\end{array}$ & $\begin{array}{l}0 \\
0,0\end{array}$ & $\begin{array}{l}3 \\
1,2\end{array}$ \\
\hline \multicolumn{12}{|c|}{ Grupo de deportes } \\
\hline Combate & $\begin{array}{l}\mathrm{N} \\
\%\end{array}$ & $\begin{array}{l}11 \\
4,2\end{array}$ & $\begin{array}{l}0 \\
0,0\end{array}$ & $\begin{array}{l}4 \\
1,7\end{array}$ & $\begin{array}{l}0 \\
0,0\end{array}$ & $\begin{array}{l}3 \\
1,2\end{array}$ & $\begin{array}{l}5 \\
2,1\end{array}$ & $\begin{array}{l}7 \\
3,0\end{array}$ & $\begin{array}{l}9 \\
3,8\end{array}$ & $\begin{array}{l}25 \\
10,7\end{array}$ & $\begin{array}{l}64 \\
27,4\end{array}$ \\
\hline Pelota & $\begin{array}{l}\mathrm{n} \\
\%\end{array}$ & $\begin{array}{l}26 \\
11,1\end{array}$ & $\begin{array}{l}0 \\
0,0\end{array}$ & $\begin{array}{l}4 \\
1,7\end{array}$ & $\begin{array}{l}13 \\
5,5\end{array}$ & $\begin{array}{l}0 \\
0,0\end{array}$ & $\begin{array}{l}0 \\
0,0\end{array}$ & $\begin{array}{l}3 \\
1,2\end{array}$ & $\begin{array}{l}12 \\
5,1\end{array}$ & $\begin{array}{l}0 \\
0,0\end{array}$ & $\begin{array}{l}58 \\
24,8\end{array}$ \\
\hline Rueda & $\begin{array}{l}\mathrm{n} \\
\%\end{array}$ & $\begin{array}{l}5 \\
2,1\end{array}$ & $\begin{array}{l}0 \\
0,0\end{array}$ & $\begin{array}{l}0 \\
0,0\end{array}$ & $\begin{array}{l}3 \\
1,2\end{array}$ & $\begin{array}{l}0 \\
0,0\end{array}$ & $\begin{array}{l}0 \\
0,0\end{array}$ & $\begin{array}{l}0 \\
0,0\end{array}$ & $\begin{array}{l}0 \\
0,0\end{array}$ & $\begin{array}{l}0 \\
0,0\end{array}$ & $\begin{array}{l}8 \\
3,4\end{array}$ \\
\hline Atlético & $\begin{array}{l}\mathrm{n} \\
\%\end{array}$ & $\begin{array}{l}20 \\
8,5\end{array}$ & $\begin{array}{l}5 \\
2,1\end{array}$ & $\begin{array}{l}9 \\
3,8\end{array}$ & $\begin{array}{l}11 \\
4,2\end{array}$ & $\begin{array}{l}5 \\
2,1\end{array}$ & $\begin{array}{l}0 \\
0,0\end{array}$ & $\begin{array}{l}8 \\
3,4\end{array}$ & $\begin{array}{l}16 \\
6,8\end{array}$ & $\begin{array}{l}29 \\
12,4\end{array}$ & $\begin{array}{l}103 \\
44,2\end{array}$ \\
\hline Total & $\begin{array}{l}\mathrm{n} \\
\%\end{array}$ & $\begin{array}{l}62 \\
26,6\end{array}$ & $\begin{array}{l}5 \\
2,1\end{array}$ & $\begin{array}{l}17 \\
7,3\end{array}$ & $\begin{array}{l}27 \\
11,5\end{array}$ & $\begin{array}{l}8 \\
3,4\end{array}$ & $\begin{array}{l}5 \\
2,1\end{array}$ & $\begin{array}{l}18 \\
7,7\end{array}$ & $\begin{array}{l}37 \\
15,8\end{array}$ & $\begin{array}{l}54 \\
23,1\end{array}$ & $\begin{array}{l}233 \\
100\end{array}$ \\
\hline
\end{tabular}

Nota COL = Colombia, CTR = Costa Rica; DOM = República Dominicana, GUA = Guatemala, MEX = México, NIC = Nicaragua, PAN = Panamá, $\mathrm{PUR}=$ Puerto Rico, VEN = Venezuela. $\mathrm{N} / \mathrm{R}=$ No responde.

La participación total más elevada corresponde a los países de Colombia y Venezuela; respecto al género, hay mayor participación femenina especialmente en
Colombia y Guatemala, en masculino predomina la participación de Venezuela. La zona residencial predominante de los participantes es la urbana con un $76,8 \%$; 
se destaca Puerto Rico y Guatemala con un porcentaje similar entre ambas zonas (urbana y rural). Se observa un aumento respecto a la participación de deportistas de instituciones públicas; con un 59,6 \%. Guatemala y Panamá presentan mayor representatividad del carácter institucional en lo privado con respecto a lo público.

\section{Organización deportiva escolar}

La organización deportiva escolar de los participantes se describe en la tabla 2.
En la organización del deporte escolar predominan los clubes deportivos, que son, también, los que más medallas aportan. La mayoría de los deportistas evaluados en los juegos pertenecen a entidades deportivas independientes de la institución, promedio más representativo en mujeres y medallistas de oro y bronce. Gran parte de las instituciones educativas no cuentan con convenios con entidades deportivas, resultado correspondiente con los porcentajes de medallistas y género.

Tabla 2. Frecuencia y porcentajes de la organización deportiva escolar según posición final (medallas) y grupos de deportes

\begin{tabular}{|c|c|c|c|c|c|c|c|c|c|c|}
\hline \multirow{2}{*}{ Variable } & & \multicolumn{4}{|c|}{ Medallas } & \multicolumn{4}{|c|}{ Grupo de deportes } & \multirow{2}{*}{ Total } \\
\hline & & Oro & Plata & Bronce & Total & Atlético & Combate & Pelota & Rueda & \\
\hline \multicolumn{11}{|c|}{ Formas en la que se organiza el deporte en la institución ${ }^{a}$} \\
\hline Club deportivo & $\begin{array}{l}\mathrm{n} \\
\%\end{array}$ & $\begin{array}{l}19 \\
41,3\end{array}$ & $\begin{array}{l}18 \\
35,2\end{array}$ & $\begin{array}{l}27 \\
46,5\end{array}$ & $\begin{array}{l}64 \\
41,2\end{array}$ & $\begin{array}{l}47 \\
38,8\end{array}$ & $\begin{array}{l}41 \\
33,8\end{array}$ & $\begin{array}{l}27 \\
40,9\end{array}$ & $\begin{array}{l}1 \\
9,0\end{array}$ & $\begin{array}{l}116 \\
41,9\end{array}$ \\
\hline $\begin{array}{l}\text { Iniciativa } \\
\text { estudiante }\end{array}$ & $\begin{array}{l}\mathrm{n} \\
\% \\
\end{array}$ & $\begin{array}{l}9 \\
19,5 \\
\end{array}$ & $\begin{array}{l}9 \\
17,6 \\
\end{array}$ & $\begin{array}{l}12 \\
20,6 \\
\end{array}$ & $\begin{array}{l}30 \\
19,3 \\
\end{array}$ & $\begin{array}{l}24 \\
19,8 \\
\end{array}$ & $\begin{array}{l}11 \\
13,9 \\
\end{array}$ & $\begin{array}{l}15 \\
22,7\end{array}$ & $\begin{array}{l}2 \\
18,1 \\
\end{array}$ & $\begin{array}{l}52 \\
18,8 \\
\end{array}$ \\
\hline $\begin{array}{l}\text { Iniciativa } \\
\text { Profesor }\end{array}$ & $\begin{array}{l}\mathrm{n} \\
\% \\
\end{array}$ & $\begin{array}{l}6 \\
13,0 \\
\end{array}$ & $\begin{array}{l}15 \\
29,4 \\
\end{array}$ & $\begin{array}{l}9 \\
15,5 \\
\end{array}$ & $\begin{array}{l}30 \\
19,3 \\
\end{array}$ & $\begin{array}{l}22 \\
18,1 \\
\end{array}$ & $\begin{array}{l}12 \\
15,1 \\
\end{array}$ & $\begin{array}{l}16 \\
24,2 \\
\end{array}$ & $\begin{array}{l}4 \\
36,3 \\
\end{array}$ & $\begin{array}{l}54 \\
19,5 \\
\end{array}$ \\
\hline Jornada Extra-Esc & $\begin{array}{l}\mathrm{n} \\
\%\end{array}$ & $\begin{array}{l}8 \\
17,3\end{array}$ & $\begin{array}{l}6 \\
11,7\end{array}$ & $\begin{array}{l}9 \\
15,5\end{array}$ & $\begin{array}{l}23 \\
14,8\end{array}$ & $\begin{array}{l}19 \\
15,7\end{array}$ & $\begin{array}{l}14 \\
17,7\end{array}$ & $\begin{array}{l}7 \\
10,6\end{array}$ & $\begin{array}{l}3 \\
27,2\end{array}$ & $\begin{array}{l}43 \\
15,52\end{array}$ \\
\hline $\mathrm{N} / \mathrm{R}$ & $\begin{array}{l}\mathrm{n} \\
\% \\
\end{array}$ & $\begin{array}{l}4 \\
8,6 \\
\end{array}$ & $\begin{array}{l}3 \\
5,8 \\
\end{array}$ & $\begin{array}{l}1 \\
1,7 \\
\end{array}$ & $\begin{array}{l}8 \\
5,1 \\
\end{array}$ & $\begin{array}{l}9 \\
7,4 \\
\end{array}$ & $\begin{array}{l}1 \\
1,2 \\
\end{array}$ & $\begin{array}{l}1 \\
1,51 \\
\end{array}$ & $\begin{array}{l}1 \\
9,0 \\
\end{array}$ & $\begin{array}{l}12 \\
4,33\end{array}$ \\
\hline \multicolumn{11}{|c|}{ Pertenencia a alguna escuela, liga o entidad deportiva independiente de su institución educativa } \\
\hline Sí & $\begin{array}{l}\mathrm{n} \\
\%\end{array}$ & $\begin{array}{l}32 \\
84,0\end{array}$ & $\begin{array}{l}26 \\
55,0\end{array}$ & $\begin{array}{l}35 \\
76,0\end{array}$ & $\begin{array}{l}93 \\
70,9\end{array}$ & $\begin{array}{l}74 \\
71,8\end{array}$ & $\begin{array}{l}45 \\
70,3\end{array}$ & $\begin{array}{l}44 \\
75,8\end{array}$ & $\begin{array}{l}5 \\
62,5\end{array}$ & $\begin{array}{l}168 \\
72,1\end{array}$ \\
\hline No & $\begin{array}{l}\mathrm{n} \\
\%\end{array}$ & $\begin{array}{l}6 \\
15,0\end{array}$ & $\begin{array}{l}21 \\
44,0\end{array}$ & $\begin{array}{l}11 \\
23,0\end{array}$ & $\begin{array}{l}38 \\
29\end{array}$ & $\begin{array}{l}28 \\
27,1\end{array}$ & $\begin{array}{l}19 \\
29,6\end{array}$ & $\begin{array}{l}14 \\
24,1\end{array}$ & $\begin{array}{l}3 \\
37,5\end{array}$ & $\begin{array}{l}64 \\
27,47\end{array}$ \\
\hline $\mathrm{N} / \mathrm{R}$ & $\begin{array}{l}\mathrm{n} \\
\%\end{array}$ & $\begin{array}{l}0 \\
0,0\end{array}$ & $\begin{array}{l}0 \\
0,0\end{array}$ & $\begin{array}{l}0 \\
0,0\end{array}$ & $\begin{array}{l}0 \\
0,0\end{array}$ & $\begin{array}{l}1 \\
0,9\end{array}$ & $\begin{array}{l}0 \\
0,0\end{array}$ & $\begin{array}{l}0 \\
0,0\end{array}$ & $\begin{array}{l}0 \\
0,0\end{array}$ & $\begin{array}{l}1 \\
0,43\end{array}$ \\
\hline \multicolumn{11}{|c|}{ Existencia de convenios con escuelas, ligas, clubes para la preparación deportiva } \\
\hline $\mathrm{Si}$ & $\begin{array}{l}\mathrm{n} \\
\%\end{array}$ & $\begin{array}{l}12 \\
31,5 \\
\end{array}$ & $\begin{array}{l}10 \\
21,2\end{array}$ & $\begin{array}{l}20 \\
43,4 \\
\end{array}$ & $\begin{array}{l}42 \\
32,0 \\
\end{array}$ & $\begin{array}{l}35 \\
33,9 \\
\end{array}$ & $\begin{array}{l}19 \\
29,6 \\
\end{array}$ & $\begin{array}{l}24 \\
41,3\end{array}$ & $\begin{array}{l}1 \\
12,5\end{array}$ & $\begin{array}{l}79 \\
33,3\end{array}$ \\
\hline No & $\begin{array}{l}\mathrm{n} \\
\% \\
\end{array}$ & $\begin{array}{l}25 \\
65,7 \\
\end{array}$ & $\begin{array}{l}35 \\
74,4 \\
\end{array}$ & $\begin{array}{l}26 \\
56,5 \\
\end{array}$ & $\begin{array}{l}86 \\
65,6 \\
\end{array}$ & $\begin{array}{l}66 \\
64,0 \\
\end{array}$ & $\begin{array}{l}44 \\
68,7 \\
\end{array}$ & $\begin{array}{l}33 \\
56,8 \\
\end{array}$ & $\begin{array}{l}7 \\
87,5 \\
\end{array}$ & $\begin{array}{l}150 \\
64,4 \\
\end{array}$ \\
\hline $\mathrm{N} / \mathrm{R}$ & $\begin{array}{l}\mathrm{n} \\
\%\end{array}$ & $\begin{array}{l}1 \\
2,6\end{array}$ & $\begin{array}{l}2 \\
4,2\end{array}$ & $\begin{array}{l}0 \\
0,0\end{array}$ & $\begin{array}{l}3 \\
2,2\end{array}$ & $\begin{array}{l}2 \\
1,9\end{array}$ & $\begin{array}{l}1 \\
1,5\end{array}$ & $\begin{array}{l}1 \\
1,7\end{array}$ & $\begin{array}{l}0 \\
0,0\end{array}$ & $\begin{array}{l}4 \\
1,7\end{array}$ \\
\hline
\end{tabular}

Nota: a = El participante tenía la opción de elegir múltiple respuesta. N/R = No responde

Al respecto se puede ratificar la discusión entre el deporte escolar y deporte en edad escolar, de los cuales el último tiene aparición en certámenes internacionales como este, donde la información recolectada da cuenta de que la formación de dichos deportistas se da especialmente en entidades deportivas independientes de la institución educativa. Hoyos (2012) expresa la disyunción entre estas dos modalidades del deporte, donde los principios cambian de manera sustancial en sus finalidades educativas y quienes los orientan. También se encuentran autores como Blázquez (1999), quien expresa que los ámbitos del deporte en edad escolar son los centros escolares, los clubes deportivos, ayuntamientos, empresas de servicios deportivos y otras asociaciones. El autor agrega que frente a los clubes 
deportivos ya es hora de desechar juicios o afirmaciones que aducen que todo lo que hace el deporte escolar en los centros educativos es bueno, mientras que lo que se hace en los clubes debe ser puesto en duda; en este sentido, Blázquez manifiesta la posibilidad de establecer convenios entre las instituciones educativas y las entidades deportivas con el fin de optimizar dichos procesos.

\section{Evaluación en el proceso del deporte escolar}

Ante la cuestión de conocer el uso de pruebas para valorar si hay aptitudes y los tipos de pruebas empleadas, los resultados encontrados se describen en la tabla 3.

Los deportistas fueron interrogados acerca de si se les aplicaron pruebas para identificar aptitudes para el deporte antes de ingresar a los programas deportivos. La mayoría contestó afirmativamente $(52,4 \%)$. Sin embargo, solamente el 14,2 \% informó que les hicieron todas las mediciones: antropométricas, de condición física, habilidades técnicas y otras médico-deportivas. En función de la clasificación final de países por medallas de oro, se pudo constatar que entre los tres primeros clasificados fue evaluado previamente un $54,7 \%$ de sus deportistas, entre los siguientes clasificados un 51,1\% y en el último grupo, un 45,4%. Se observó que los países peor clasificados dan mayor énfasis a las pruebas de la condición física, mientras en los mejor clasificados se presentó una mayor utilización de las diferentes áreas de evaluación. En función de los grupos de deportes, se evidenció que las pruebas fueron utilizadas en los deportes atléticos $(60,2 \%)$, seguido de los de pelota $(48,3 \%)$, de combate $(45,3 \%)$ y los de ruedas $(37,5 \%)$.

Los resultados muestran que se detectaron los talentos para ingresar a los procesos de formación deportiva sin un criterio científico suficiente, puesto que idealmente las pruebas de detección deberían abarcar a toda la población infantil y escolar, y solo a uno de cada seis deportistas evaluados se les aplicaron pruebas de todos los factores indagados.

Tabla 3. Utilización de pruebas para establecer el talento para el deporte, según posición final (medallas) y grupos de deportes

\begin{tabular}{|c|c|c|c|c|c|c|c|c|c|c|}
\hline \multirow{2}{*}{ Variable } & & \multicolumn{4}{|c|}{ Medallas } & \multicolumn{4}{|c|}{ Grupo de deportes } & \multirow{2}{*}{ Total } \\
\hline & & Oro & Plata & Bronce & Total & Atlético & Combate & Pelota & Rueda & \\
\hline \multicolumn{11}{|c|}{ Aplicación de pruebas para saber si tenía aptitudes } \\
\hline Sí & $\begin{array}{l}\mathrm{n} \\
\%\end{array}$ & $\begin{array}{l}25 \\
65,8\end{array}$ & $\begin{array}{l}14 \\
29,8\end{array}$ & $\begin{array}{l}26 \\
56,5\end{array}$ & $\begin{array}{l}65 \\
49,6\end{array}$ & $\begin{array}{l}62 \\
60,2\end{array}$ & $\begin{array}{l}29 \\
45,3\end{array}$ & $\begin{array}{l}28 \\
48,3\end{array}$ & $\begin{array}{l}3 \\
37,5\end{array}$ & $\begin{array}{l}122 \\
52,4\end{array}$ \\
\hline No & $\begin{array}{l}\mathrm{n} \\
\%\end{array}$ & $\begin{array}{l}13 \\
34,2\end{array}$ & $\begin{array}{l}30 \\
63,8\end{array}$ & $\begin{array}{l}20 \\
43,5\end{array}$ & $\begin{array}{l}63 \\
48,1\end{array}$ & $\begin{array}{l}35 \\
34,0\end{array}$ & $\begin{array}{l}34 \\
53,1\end{array}$ & $\begin{array}{l}29 \\
50,0\end{array}$ & $\begin{array}{l}5 \\
62,5\end{array}$ & $\begin{array}{l}103 \\
44,2\end{array}$ \\
\hline $\mathrm{N} / \mathrm{R}$ & $\begin{array}{l}\mathrm{n} \\
\%\end{array}$ & $\begin{array}{l}0 \\
0,0\end{array}$ & $\begin{array}{l}3 \\
6,4\end{array}$ & $\begin{array}{l}0 \\
0,0\end{array}$ & $\begin{array}{l}3 \\
2,3\end{array}$ & $\begin{array}{l}6 \\
5,8\end{array}$ & $\begin{array}{l}1 \\
1,6\end{array}$ & $\begin{array}{l}1 \\
1,7\end{array}$ & $\begin{array}{l}0 \\
0,0\end{array}$ & $\begin{array}{l}8 \\
3,4\end{array}$ \\
\hline
\end{tabular}

Tipo de pruebas utilizadas para identificar el talento ${ }^{\mathrm{a}}$

\begin{tabular}{|c|c|c|c|c|c|c|c|c|c|c|}
\hline $\begin{array}{l}\text { Medidas } \\
\text { corporales }\end{array}$ & $\begin{array}{l}\mathrm{n} \\
\%\end{array}$ & $\begin{array}{l}5 \\
14,7\end{array}$ & $\begin{array}{l}1 \\
5,0\end{array}$ & $\begin{array}{l}5 \\
13,5\end{array}$ & $\begin{array}{l}11 \\
12,1\end{array}$ & $\begin{array}{l}10 \\
11,6\end{array}$ & $\begin{array}{l}5 \\
10,0\end{array}$ & $\begin{array}{l}4 \\
9,3\end{array}$ & $\begin{array}{l}0 \\
0,0\end{array}$ & $\begin{array}{l}19 \\
10,4\end{array}$ \\
\hline Pruebas físicas & $\begin{array}{l}\mathrm{n} \\
\%\end{array}$ & $\begin{array}{l}12 \\
35,3\end{array}$ & $\begin{array}{l}8 \\
40,0\end{array}$ & $\begin{array}{l}16 \\
43,2\end{array}$ & $\begin{array}{l}36 \\
39,6\end{array}$ & $\begin{array}{l}38 \\
44,2\end{array}$ & $\begin{array}{l}21 \\
42,0\end{array}$ & $\begin{array}{l}18 \\
41,9\end{array}$ & $\begin{array}{l}3 \\
7,0\end{array}$ & $\begin{array}{l}80 \\
44\end{array}$ \\
\hline $\begin{array}{l}\text { Habilidades } \\
\text { técnicas }\end{array}$ & $\begin{array}{l}\mathrm{n} \\
\%\end{array}$ & $\begin{array}{l}13 \\
38,2\end{array}$ & $\begin{array}{l}6 \\
30,0\end{array}$ & $\begin{array}{l}11 \\
29,7\end{array}$ & $\begin{array}{l}30 \\
33,0\end{array}$ & $\begin{array}{l}22 \\
25,6\end{array}$ & $\begin{array}{l}14 \\
28,0\end{array}$ & $\begin{array}{l}16 \\
37,2\end{array}$ & $\begin{array}{l}0 \\
0,0\end{array}$ & $\begin{array}{l}52 \\
28,6\end{array}$ \\
\hline Médico deportivas & $\begin{array}{l}\mathrm{n} \\
\%\end{array}$ & $\begin{array}{l}4 \\
11,7\end{array}$ & $\begin{array}{l}1 \\
5\end{array}$ & $\begin{array}{l}4 \\
10,8\end{array}$ & $\begin{array}{l}9 \\
9,9\end{array}$ & $\begin{array}{l}8 \\
9,3\end{array}$ & $\begin{array}{l}7 \\
14,0\end{array}$ & $\begin{array}{l}4 \\
9,3\end{array}$ & $\begin{array}{l}0 \\
0,0\end{array}$ & $\begin{array}{l}19 \\
10,4\end{array}$ \\
\hline N/R & $\begin{array}{l}\mathrm{n} \\
\%\end{array}$ & $\begin{array}{l}0 \\
0,0\end{array}$ & $\begin{array}{l}4 \\
20,0\end{array}$ & $\begin{array}{l}1 \\
2,7\end{array}$ & $\begin{array}{l}5 \\
5,5\end{array}$ & $\begin{array}{l}8 \\
9,3\end{array}$ & $\begin{array}{l}3 \\
6,0\end{array}$ & $\begin{array}{l}1 \\
2,3\end{array}$ & $\begin{array}{l}0 \\
0,0\end{array}$ & $\begin{array}{l}12 \\
6,6\end{array}$ \\
\hline
\end{tabular}

Nota: a = El participante tenía la opción de elegir múltiple respuesta. $\mathrm{N} / \mathrm{R}=$ No responde

Diversos autores (Dias, Pereira, Negrão, y Krieger, 2007; Hopkins, 2001) aseguran que los genes son responsables por cerca de la mitad de la variación del rendimiento físico entre individuos de una población, también que los genes dan cuenta por la mitad de la variación en la respuesta al entrenamiento físico y que son probablemente aún más importantes que el entrenamiento en la explicación de las diferencias en el rendimiento entre atletas (Serguienko, 2004). La identificación de talentos y la selección de pares apropiados, por lo tanto, son aproximaciones lógicas para 
la creación de élites deportivas, lo cual no se aprecia en la muestra evaluada, donde se siguen seleccionando futuros deportistas a partir de rendimientos en edades infantiles pese a que está ampliamente demostrado que "el rendimiento no predice el rendimiento" (Durand, 1988).

Frente a lo señalado por Pahkhurst, Collins, y Macnamara (2013), y previamente mencionado en el estudio de Alzate, Ayala, y Melo (2012), de que no hay acuerdo entre entrenadores, padres y administradores respecto a la aplicación de los aspectos claves para el desarrollo del talento deportivo; se evidencia en los datos que por lo menos cerca de la mitad de los entrenadores no dan suficiente importancia al uso de procedimientos científicos en la fase inicial de dicho proceso, la detección del talento.

Algunos países del este europeo empezaron sus programas de identificación de talentos en la década del 70 , lo cual se constituyó en uno de los pilares de su desarrollo deportivo (Werkiani, Zakizadeh, Golsefidi, y Rahimi, 2012). Así mismo, Hahn (1988) comprobó que una apropiada identificación de talentos fue el factor prioritario para el éxito de los países del este europeo en décadas recientes, lo cual aún no se refleja en las prácticas de la muestra.

Tabla 4. Frecuencia y porcentaje del uso de las pruebas para el control del entrenamiento, según posición final (medallas) y grupos de deportes

\begin{tabular}{|c|c|c|c|c|c|c|c|c|c|c|}
\hline \multirow{2}{*}{ Variable } & & \multicolumn{4}{|c|}{ Medallas } & \multicolumn{4}{|c|}{ Grupo de deportes } & \multirow{2}{*}{ Total } \\
\hline & & Oro & Plata & Bronce & Total & Atlético & Combate & Pelota & Rueda & \\
\hline \multicolumn{10}{|c|}{ Aplicación de pruebas a lo largo del proceso } & \\
\hline Sí & $\begin{array}{l}\mathrm{n} \\
\%\end{array}$ & \begin{tabular}{|l|}
37 \\
97,3
\end{tabular} & \begin{tabular}{|l|}
39 \\
82,9
\end{tabular} & \begin{tabular}{|l|}
42 \\
91,3
\end{tabular} & $\begin{array}{l}118 \\
90,0\end{array}$ & \begin{tabular}{|l|}
89 \\
86,4
\end{tabular} & $\begin{array}{l}58 \\
90,6\end{array}$ & \begin{tabular}{|l|}
53 \\
91,3
\end{tabular} & \begin{tabular}{|l|}
8 \\
100
\end{tabular} & $\begin{array}{l}208 \\
89,3\end{array}$ \\
\hline No & $\begin{array}{l}\mathrm{n} \\
\%\end{array}$ & $\begin{array}{l}1 \\
2,6 \\
\end{array}$ & $\begin{array}{l}5 \\
10,6\end{array}$ & $\begin{array}{l}4 \\
8,6 \\
\end{array}$ & $\begin{array}{l}10 \\
7,6 \\
\end{array}$ & $\begin{array}{l}7 \\
6,7 \\
\end{array}$ & $\begin{array}{l}5 \\
7,8 \\
\end{array}$ & $\begin{array}{l}4 \\
6,8 \\
\end{array}$ & $\begin{array}{l}0 \\
0,0\end{array}$ & $\begin{array}{l}16 \\
6,9\end{array}$ \\
\hline $\mathrm{N} / \mathrm{R}$ & $\begin{array}{l}\mathrm{n} \\
\%\end{array}$ & $\begin{array}{l}0 \\
0,0\end{array}$ & $\begin{array}{l}3 \\
6,3\end{array}$ & $\begin{array}{l}0 \\
0,0\end{array}$ & \begin{tabular}{|l|}
3 \\
2,2 \\
\end{tabular} & $\begin{array}{l}7 \\
6,7\end{array}$ & $\begin{array}{l}1 \\
1,5\end{array}$ & $\begin{array}{l}1 \\
1,7 \\
\end{array}$ & $\begin{array}{l}0 \\
0,0\end{array}$ & $\begin{array}{l}9 \\
3,9 \\
\end{array}$ \\
\hline \multicolumn{11}{|c|}{ Tipo de pruebas utilizadas para el control del entrenamiento ${ }^{a}$} \\
\hline $\begin{array}{l}\text { Medidas } \\
\text { corporales }\end{array}$ & $\begin{array}{l}\mathrm{n} \\
\% \\
\end{array}$ & $\begin{array}{l}12 \\
13,4 \\
\end{array}$ & $\begin{array}{l}12 \\
12,6 \\
\end{array}$ & $\begin{array}{l}21 \\
18,7\end{array}$ & $\begin{array}{l}45 \\
15,2 \\
\end{array}$ & \begin{tabular}{|l|}
34 \\
16,9 \\
\end{tabular} & $\begin{array}{l}27 \\
15,5 \\
\end{array}$ & $\begin{array}{l}11 \\
9,4 \\
\end{array}$ & \begin{tabular}{|l|}
6 \\
22,2 \\
\end{tabular} & $\begin{array}{l}78 \\
15 \\
\end{array}$ \\
\hline Pruebas físicas & $\begin{array}{l}\mathrm{n} \\
\%\end{array}$ & \begin{tabular}{|l|}
33 \\
37,0 \\
\end{tabular} & $\begin{array}{l}31 \\
32,6 \\
\end{array}$ & \begin{tabular}{|l|}
36 \\
32,1 \\
\end{tabular} & $\begin{array}{l}100 \\
33,7 \\
\end{array}$ & $\begin{array}{l}67 \\
33,3 \\
\end{array}$ & \begin{tabular}{|l|}
50 \\
28,7
\end{tabular} & \begin{tabular}{|l|}
44 \\
37,6 \\
\end{tabular} & \begin{tabular}{|l|}
7 \\
25,9 \\
\end{tabular} & $\begin{array}{l}168 \\
32,4\end{array}$ \\
\hline Habilidades técnicas & $\begin{array}{l}\mathrm{n} \\
\%\end{array}$ & \begin{tabular}{|l|}
16 \\
17,9 \\
\end{tabular} & $\begin{array}{l}22 \\
23,1\end{array}$ & \begin{tabular}{|l|}
20 \\
17,8 \\
\end{tabular} & \begin{tabular}{|l|}
58 \\
19,5 \\
\end{tabular} & $\begin{array}{l}33 \\
16,4 \\
\end{array}$ & \begin{tabular}{|l|}
35 \\
20,1
\end{tabular} & \begin{tabular}{|l|}
29 \\
24,7 \\
\end{tabular} & \begin{tabular}{|l|}
4 \\
14,8 \\
\end{tabular} & $\begin{array}{l}101 \\
19,5\end{array}$ \\
\hline Valoración médica & $\begin{array}{l}\mathrm{n} \\
\%\end{array}$ & \begin{tabular}{|l|}
14 \\
15,7
\end{tabular} & $\begin{array}{l}13 \\
13,6\end{array}$ & \begin{tabular}{|l|}
15 \\
13,3 \\
\end{tabular} & \begin{tabular}{|l|}
42 \\
14,1 \\
\end{tabular} & $\begin{array}{l}29 \\
14,4 \\
\end{array}$ & \begin{tabular}{|l|}
32 \\
18,3 \\
\end{tabular} & \begin{tabular}{|l|}
14 \\
11,9
\end{tabular} & \begin{tabular}{|l|}
6 \\
22,2
\end{tabular} & \begin{tabular}{|l|}
81 \\
15,6 \\
\end{tabular} \\
\hline $\begin{array}{l}\text { Valoración } \\
\text { psicológica }\end{array}$ & $\begin{array}{l}\mathrm{n} \\
\%\end{array}$ & $\begin{array}{l}11 \\
12,3 \\
\end{array}$ & $\begin{array}{l}8 \\
8,4\end{array}$ & \begin{tabular}{|l|}
15 \\
13,3 \\
\end{tabular} & \begin{tabular}{|l|}
34 \\
11,4
\end{tabular} & $\begin{array}{l}22 \\
10,9\end{array}$ & \begin{tabular}{|l|}
23 \\
13,2
\end{tabular} & $\begin{array}{l}11 \\
9,4 \\
\end{array}$ & \begin{tabular}{|l|}
4 \\
14,8
\end{tabular} & \begin{tabular}{|l|}
60 \\
11,6
\end{tabular} \\
\hline $\mathrm{N} / \mathrm{R}$ & $\begin{array}{l}\mathrm{n} \\
\%\end{array}$ & $\begin{array}{l}3 \\
3,3 \\
\end{array}$ & $\begin{array}{l}9 \\
9,4\end{array}$ & $\begin{array}{l}5 \\
4,4\end{array}$ & $\begin{array}{l}17 \\
5,7 \\
\end{array}$ & $\begin{array}{l}16 \\
7,9\end{array}$ & $\begin{array}{l}7 \\
4,0 \\
\end{array}$ & $\begin{array}{l}8 \\
6,8 \\
\end{array}$ & \begin{tabular}{|l|}
0 \\
0,0 \\
\end{tabular} & $\begin{array}{l}31 \\
6 \\
\end{array}$ \\
\hline Total & $\begin{array}{l}\mathrm{n} \\
\%\end{array}$ & \begin{tabular}{|l|}
89 \\
100
\end{tabular} & \begin{tabular}{|l|}
95 \\
100
\end{tabular} & $\begin{array}{l}112 \\
100\end{array}$ & $\begin{array}{l}296 \\
100\end{array}$ & $\begin{array}{l}201 \\
100\end{array}$ & $\begin{array}{l}174 \\
100\end{array}$ & $\begin{array}{l}117 \\
100\end{array}$ & \begin{tabular}{|l|}
27 \\
100
\end{tabular} & $\begin{array}{l}519 \\
100\end{array}$ \\
\hline
\end{tabular}

Nota: a = El participante tenía la opción de elegir múltiple respuesta. $\mathrm{N} / \mathrm{R}=$ No responde

Uso de las pruebas para el control del entrenamiento

Se encuentra que al 89,2\% de los deportistas se les aplicaron pruebas de control; un porcentaje similar se encontró en los medallistas (90,0 \%). En los ganadores de medallas de oro, resalta que al 97,3\% se les aplicaron dichas pruebas. Las pruebas utilizadas para el control son las pruebas físicas con $32,3 \%$, seguidas de las habilidades deportivas con el 19,46\%; la menos utilizada es la valoración psicológica, con un $14,8 \%$. Se repite la tendencia en todos los medallistas.
Martin, Nicolaus, Ostroswski, y Rost (2004) expresan que dentro del control del entrenamiento se deben tener en cuenta procedimientos como test deportivos motores, diagnóstico del rendimiento, entrenamiento de medición, observación del movimiento y competiciones. Así como la relevancia del control biomédico, pruebas de composición corporal, lactato sanguíneo, frecuencia cardiaca, etc. (Melero, Pradas y Vargas, 
CARACTERÍSTICAS DE LA FORMACIÓN DEPORTIVA DE LOS PARTICIPANTES

EN LOS IV JUEGOS ESCOLARES CENTROAMERICANOS Y DEL CARIBE, ARMENIA 2013

Adriana María Agudelo G. / Carlos Federico Ayala Z. / Santiago Ramos B. / Angélica María García G. / Luis Gerardo Melo/

Héctor Haney Aguirre-Loaiza / Luisa Fernanda Gutiérrez A. / Hernando Alejandro Martínez / Kelly Marcela Ovalle Martínez

2005), así como la constante sugerencia de programas de intervención psicológica en los diferentes actores del deporte (Aguirre-Loaiza y Ramos, 2011; Aguirre-Loaiza, Ramos y Agudelo, 2015; Arenas y Aguirre-Loaiza, 2014; Olmedilla, Ortega, Boladeras, Ortín, Bazaco, 2013).

\section{Procesos de iniciación deportiva}

Con respecto a la iniciación deportiva de los participantes, fueron estudiados los componentes de la edad de inicio, el tipo de programa de formación y lugar donde se inició la formación. Los datos descriptivos se enuncian en la tabla 5.

Tabla 5. Frecuencia y porcentaje de las características del proceso de iniciación deportiva, según posición final (medallas) y grupos de deportes

\begin{tabular}{|c|c|c|c|c|c|c|c|c|c|c|}
\hline \multirow{2}{*}{ Variable } & & \multicolumn{4}{|c|}{ Medallas } & \multicolumn{4}{|c|}{ Grupo de deportes } & \multirow{2}{*}{ Total } \\
\hline & & Oro & Plata & Bronce & Total & Atlético & Combate & Pelota & Rueda & \\
\hline \multicolumn{11}{|c|}{ Edad en la que inició su formación deportiva (en años) } \\
\hline $1-4$ & $\begin{array}{l}\mathrm{n} \\
\% \\
\end{array}$ & $\begin{array}{l}5 \\
13,1 \\
\end{array}$ & $\begin{array}{l}1 \\
2,2 \\
\end{array}$ & $\begin{array}{l}2 \\
4,1 \\
\end{array}$ & $\begin{array}{l}8 \\
6,1 \\
\end{array}$ & $\begin{array}{l}5 \\
4,9 \\
\end{array}$ & $\begin{array}{l}5 \\
8,0 \\
\end{array}$ & $\begin{array}{l}4 \\
6,7 \\
\end{array}$ & $\begin{array}{l}3 \\
30,0 \\
\end{array}$ & $\begin{array}{l}17 \\
7,29\end{array}$ \\
\hline $5-7$ & $\begin{array}{l}\mathrm{n} \\
\%\end{array}$ & $\begin{array}{l}11 \\
28,9\end{array}$ & $\begin{array}{l}11 \\
24,4\end{array}$ & $\begin{array}{l}6 \\
12,5\end{array}$ & $\begin{array}{l}28 \\
21,3\end{array}$ & $\begin{array}{l}22 \\
21,5\end{array}$ & $\begin{array}{l}13 \\
20,9\end{array}$ & $\begin{array}{l}6 \\
10,1\end{array}$ & $\begin{array}{l}2 \\
20,0\end{array}$ & $\begin{array}{l}43 \\
18,5\end{array}$ \\
\hline 8-10 & $\begin{array}{l}\mathrm{n} \\
\%\end{array}$ & $\begin{array}{l}7 \\
18,4\end{array}$ & $\begin{array}{l}22 \\
48,8\end{array}$ & $\begin{array}{l}13 \\
27,0\end{array}$ & $\begin{array}{l}42 \\
32,0\end{array}$ & $\begin{array}{l}24 \\
23,5\end{array}$ & $\begin{array}{l}19 \\
30,6\end{array}$ & $\begin{array}{l}25 \\
42,3\end{array}$ & $\begin{array}{l}3 \\
30,0\end{array}$ & $\begin{array}{l}71 \\
30,5\end{array}$ \\
\hline $11-13$ & $\begin{array}{l}\mathrm{n} \\
\%\end{array}$ & $\begin{array}{l}11 \\
28,9\end{array}$ & $\begin{array}{l}10 \\
22,2\end{array}$ & $\begin{array}{l}21 \\
43,7\end{array}$ & $\begin{array}{l}42 \\
32,0\end{array}$ & $\begin{array}{l}33 \\
32,3\end{array}$ & $\begin{array}{l}18 \\
29,0\end{array}$ & $\begin{array}{l}23 \\
38,9\end{array}$ & $\begin{array}{l}2 \\
20,0\end{array}$ & $\begin{array}{l}76 \\
32,6\end{array}$ \\
\hline $14-15$ & $\begin{array}{l}\mathrm{n} \\
\%\end{array}$ & $\begin{array}{l}3 \\
7,8\end{array}$ & $\begin{array}{l}0 \\
0,0\end{array}$ & $\begin{array}{l}4 \\
8,3\end{array}$ & $\begin{array}{l}7 \\
5,3\end{array}$ & $\begin{array}{l}16 \\
15,6\end{array}$ & $\begin{array}{l}6 \\
9,6\end{array}$ & $\begin{array}{l}0 \\
0,0\end{array}$ & $\begin{array}{l}0 \\
0,0\end{array}$ & $\begin{array}{l}22 \\
9,4\end{array}$ \\
\hline $\mathrm{N} / \mathrm{R}$ & $\begin{array}{l}\mathrm{n} \\
\%\end{array}$ & $\begin{array}{l}1 \\
2,6\end{array}$ & $\begin{array}{l}1 \\
2,2\end{array}$ & $\begin{array}{l}2 \\
4,1\end{array}$ & $\begin{array}{l}4 \\
3,0\end{array}$ & $\begin{array}{l}2 \\
1,9\end{array}$ & $\begin{array}{l}1 \\
1,6\end{array}$ & $\begin{array}{l}1 \\
1,6\end{array}$ & $\begin{array}{l}0 \\
0,0\end{array}$ & $\begin{array}{l}4 \\
1,7\end{array}$ \\
\hline \multicolumn{11}{|c|}{ Tipo de programa en el que inició la formación deportiva } \\
\hline Especializado & $\begin{array}{l}\mathrm{n} \\
\%\end{array}$ & $\begin{array}{l}29 \\
76,3\end{array}$ & $\begin{array}{l}30 \\
63,8\end{array}$ & $\begin{array}{l}31 \\
67,3\end{array}$ & $\begin{array}{l}90 \\
68,7\end{array}$ & $\begin{array}{l}59 \\
57,2\end{array}$ & $\begin{array}{l}48 \\
75,0\end{array}$ & $\begin{array}{l}44 \\
75,8\end{array}$ & $\begin{array}{l}7 \\
87,5\end{array}$ & $\begin{array}{l}158 \\
67,8\end{array}$ \\
\hline Polidepor & $\begin{array}{l}\mathrm{n} \\
\%\end{array}$ & $\begin{array}{l}8 \\
21,0\end{array}$ & $\begin{array}{l}14 \\
29,7\end{array}$ & $\begin{array}{l}15 \\
32,6\end{array}$ & $\begin{array}{l}37 \\
28,2\end{array}$ & $\begin{array}{l}37 \\
35,9\end{array}$ & $\begin{array}{l}15 \\
23,4\end{array}$ & $\begin{array}{l}11 \\
18,9\end{array}$ & $\begin{array}{l}1 \\
12,5\end{array}$ & $\begin{array}{l}64 \\
27,5\end{array}$ \\
\hline $\mathrm{N} / \mathrm{R}$ & $\begin{array}{l}\mathrm{n} \\
\%\end{array}$ & $\begin{array}{l}1 \\
2,6\end{array}$ & $\begin{array}{l}3 \\
6,3 \\
\end{array}$ & $\begin{array}{l}0 \\
0,0 \\
\end{array}$ & $\begin{array}{l}4 \\
3,0 \\
\end{array}$ & $\begin{array}{l}7 \\
6,7 \\
\end{array}$ & $\begin{array}{l}1 \\
1,5 \\
\end{array}$ & $\begin{array}{l}3 \\
5,1\end{array}$ & $\begin{array}{l}0 \\
0,0\end{array}$ & $\begin{array}{l}11 \\
4,7\end{array}$ \\
\hline \multicolumn{11}{|c|}{ Lugar donde inició su formación deportiva ${ }^{a}$} \\
\hline Club & $\begin{array}{l}\mathrm{n} \\
\%\end{array}$ & $\begin{array}{l}18 \\
45,0\end{array}$ & $\begin{array}{l}19 \\
38,7\end{array}$ & $\begin{array}{l}17 \\
36,9\end{array}$ & $\begin{array}{l}54 \\
40,0\end{array}$ & $\begin{array}{l}42 \\
40,0\end{array}$ & $\begin{array}{l}42 \\
64,6\end{array}$ & $\begin{array}{l}13 \\
21,6\end{array}$ & $\begin{array}{l}2 \\
25\end{array}$ & $\begin{array}{l}99 \\
41,6\end{array}$ \\
\hline Escuela deportiva & $\begin{array}{l}\mathrm{n} \\
\%\end{array}$ & $\begin{array}{l}8 \\
20,0\end{array}$ & $\begin{array}{l}11 \\
22,4\end{array}$ & $\begin{array}{l}7 \\
15,2\end{array}$ & $\begin{array}{l}26 \\
19,2\end{array}$ & $\begin{array}{l}19 \\
18,0\end{array}$ & $\begin{array}{l}12 \\
18,4\end{array}$ & $\begin{array}{l}8 \\
13,3\end{array}$ & $\begin{array}{l}5 \\
62,5\end{array}$ & $\begin{array}{l}44 \\
18,5\end{array}$ \\
\hline Liga & $\begin{array}{l}\mathrm{n} \\
\%\end{array}$ & $\begin{array}{l}6 \\
15,0\end{array}$ & $\begin{array}{l}3 \\
6,1\end{array}$ & $\begin{array}{l}6 \\
13,0\end{array}$ & $\begin{array}{l}15 \\
11,1\end{array}$ & $\begin{array}{l}13 \\
12,3\end{array}$ & $\begin{array}{l}5 \\
7,6\end{array}$ & $\begin{array}{l}12 \\
20,0\end{array}$ & $\begin{array}{l}0 \\
0,0\end{array}$ & $\begin{array}{l}30 \\
12,6\end{array}$ \\
\hline Institución educativa & $\begin{array}{l}\mathrm{n} \\
\%\end{array}$ & $\begin{array}{l}6 \\
15,0\end{array}$ & $\begin{array}{l}15 \\
30,6\end{array}$ & $\begin{array}{l}13 \\
28,2\end{array}$ & $\begin{array}{l}34 \\
25,1\end{array}$ & $\begin{array}{l}25 \\
23,8\end{array}$ & $\begin{array}{l}6 \\
9,2\end{array}$ & $\begin{array}{l}23 \\
38,3\end{array}$ & $\begin{array}{l}0 \\
0,0\end{array}$ & $\begin{array}{l}54 \\
22,7\end{array}$ \\
\hline Otro & $\begin{array}{l}\mathrm{n} \\
\%\end{array}$ & $\begin{array}{l}1 \\
2,5\end{array}$ & $\begin{array}{l}1 \\
2,0\end{array}$ & $\begin{array}{l}2 \\
4,3\end{array}$ & $\begin{array}{l}4 \\
2,9\end{array}$ & $\begin{array}{l}3 \\
2,8\end{array}$ & $\begin{array}{l}0 \\
0,0\end{array}$ & $\begin{array}{l}3 \\
5,0\end{array}$ & $\begin{array}{l}1 \\
12,5\end{array}$ & $\begin{array}{l}7 \\
2,9\end{array}$ \\
\hline $\mathrm{N} / \mathrm{R}$ & $\begin{array}{l}\mathrm{n} \\
\%\end{array}$ & $\begin{array}{l}1 \\
2,5\end{array}$ & $\begin{array}{l}0 \\
0,0\end{array}$ & $\begin{array}{l}1 \\
2,1\end{array}$ & $\begin{array}{l}2 \\
1,4\end{array}$ & $\begin{array}{l}3 \\
2,8\end{array}$ & $\begin{array}{l}0 \\
0,0\end{array}$ & $\begin{array}{l}1 \\
1,6\end{array}$ & $\begin{array}{l}0 \\
0,0\end{array}$ & $\begin{array}{l}4 \\
1,7\end{array}$ \\
\hline Total & $\begin{array}{l}\mathrm{n} \\
\%\end{array}$ & $\begin{array}{l}40 \\
100\end{array}$ & $\begin{array}{l}49 \\
100\end{array}$ & $\begin{array}{l}46 \\
100\end{array}$ & $\begin{array}{l}135 \\
100\end{array}$ & $\begin{array}{l}105 \\
100\end{array}$ & $\begin{array}{l}65 \\
100\end{array}$ & $\begin{array}{l}60 \\
100\end{array}$ & $\begin{array}{l}8 \\
100\end{array}$ & $\begin{array}{l}238 \\
100\end{array}$ \\
\hline
\end{tabular}

Nota: a = El participante tenía la opción de elegir múltiple respuesta. N/R = No responde. 
Al total de deportistas centroamericanos encuestados se les preguntó sobre la edad de inicio en su proceso de formación deportiva, el $50 \%$ lo hizo entre los 10 y 13 años de edad, la edad promedio de inicio es de 9,57 años. Estos resultados dan cuenta de que la mayoría (60\%) de los deportistas están iniciando su proceso en lo que los teóricos llaman fase o etapa de seguimiento y otros en la de especialización (Blázquez, 1999; Platonov, 1999), lo que los pone en posible desventaja frente a poblaciones europeas, socialistas y anglosajonas en relación con un proceso planificado de la preparación deportiva a largo plazo.

Para las variables de medallistas y grupos de deportes la iniciación deportiva se da en programas especializados y no polideportivos, esto quiere decir que el proceso de iniciación se dio por medio de la adquisición de habili- dades y destrezas configuradas en una sola modalidad deportiva, y no a través de la experimentación de varias modalidades deportivas. Respecto al lugar de inicio, se encuentra que la iniciación se da principalmente en entidades de fomento al deporte con un $77 \%$ y solo $22,68 \%$ se iniciaron en una institución educativa, lo que demuestra que dentro de la muestra evaluada de escolares participantes en los Juegos Centroamericanos la representatividad del deporte escolar es baja y se enfoca especialmente en el deporte en edad escolar.

\section{Características de la competencia}

El máximo nivel de la competencia y el número de competencias de participación por año fueron variables objeto que permitieron describir las características de competencia de los deportistas escolares (tabla 6).

Tabla 6. Frecuencia y porcentaje de las características de la competencia entre los deportistas posición final (medallas) y grupos de deportes

\begin{tabular}{|c|c|c|c|c|c|c|c|c|c|c|}
\hline \multirow{2}{*}{ Variable } & & \multicolumn{4}{|c|}{ Medallas } & \multicolumn{4}{|c|}{ Grupo de deportes } & \multirow{2}{*}{ Total } \\
\hline & & Oro & Plata & Bronce & Total & Atlético & Combate & Pelota & Rueda & \\
\hline \multicolumn{11}{|c|}{ Nivel máximo en el que se ha competido } \\
\hline Mundial & $\begin{array}{l}\mathrm{n} \\
\%\end{array}$ & $\begin{array}{l}8 \\
21,0\end{array}$ & $\begin{array}{l}6 \\
12,7\end{array}$ & $\begin{array}{l}6 \\
13,0\end{array}$ & $\begin{array}{l}20 \\
15,2\end{array}$ & $\begin{array}{l}21 \\
20,3\end{array}$ & $\begin{array}{l}8 \\
12,5\end{array}$ & $\begin{array}{l}3 \\
5,17\end{array}$ & $\begin{array}{l}2 \\
25\end{array}$ & $\begin{array}{l}34 \\
14,6\end{array}$ \\
\hline Panamericano & $\begin{array}{l}\mathrm{n} \\
\%\end{array}$ & $\begin{array}{l}9 \\
23,6\end{array}$ & $\begin{array}{l}8 \\
17,0\end{array}$ & $\begin{array}{l}12 \\
26,0\end{array}$ & $\begin{array}{l}29 \\
22,1\end{array}$ & $\begin{array}{l}15 \\
14,5\end{array}$ & $\begin{array}{l}22 \\
34,3\end{array}$ & $\begin{array}{l}9 \\
15,5\end{array}$ & $\begin{array}{l}1 \\
12,5\end{array}$ & $\begin{array}{l}47 \\
20,2\end{array}$ \\
\hline Centroamericano & $\begin{array}{l}\mathrm{n} \\
\%\end{array}$ & $\begin{array}{l}16 \\
42,1\end{array}$ & $\begin{array}{l}26 \\
55,3\end{array}$ & $\begin{array}{l}16 \\
34,7\end{array}$ & $\begin{array}{l}58 \\
44,2\end{array}$ & $\begin{array}{l}52 \\
50,4\end{array}$ & $\begin{array}{l}21 \\
32,8\end{array}$ & $\begin{array}{l}30 \\
51,7\end{array}$ & $\begin{array}{l}4 \\
50,0\end{array}$ & $\begin{array}{l}107 \\
45,9\end{array}$ \\
\hline Suramericano & $\begin{array}{l}\mathrm{n} \\
\%\end{array}$ & $\begin{array}{l}3 \\
7,8\end{array}$ & $\begin{array}{l}4 \\
8,5\end{array}$ & $\begin{array}{l}5 \\
10,8\end{array}$ & $\begin{array}{l}12 \\
9,1\end{array}$ & $\begin{array}{l}6 \\
5,8\end{array}$ & $\begin{array}{l}5 \\
7,8\end{array}$ & $\begin{array}{l}6 \\
10,3\end{array}$ & $\begin{array}{l}1 \\
12,5\end{array}$ & $\begin{array}{l}18 \\
7,7\end{array}$ \\
\hline Nacional & $\begin{array}{l}\mathrm{n} \\
\%\end{array}$ & $\begin{array}{l}2 \\
5,2\end{array}$ & $\begin{array}{l}2 \\
4,2\end{array}$ & $\begin{array}{l}7 \\
15,2\end{array}$ & $\begin{array}{l}11 \\
8,3\end{array}$ & $\begin{array}{l}8 \\
7,7\end{array}$ & $\begin{array}{l}6 \\
9,3\end{array}$ & $\begin{array}{l}10 \\
17,2\end{array}$ & $\begin{array}{l}0 \\
0,0\end{array}$ & $\begin{array}{l}24 \\
10,3\end{array}$ \\
\hline Ninguno & $\begin{array}{l}\mathrm{n} \\
\%\end{array}$ & $\begin{array}{l}0 \\
0,0\end{array}$ & $\begin{array}{l}1 \\
2,1\end{array}$ & $\begin{array}{l}0 \\
0,0\end{array}$ & $\begin{array}{l}1 \\
0,7\end{array}$ & $\begin{array}{l}0 \\
0,0\end{array}$ & $\begin{array}{l}2 \\
3,1\end{array}$ & $\begin{array}{l}0 \\
0,0\end{array}$ & $\begin{array}{l}0 \\
0,0\end{array}$ & $\begin{array}{l}2 \\
0,9\end{array}$ \\
\hline Otro & $\begin{array}{l}\mathrm{n} \\
\%\end{array}$ & $\begin{array}{l}0 \\
0,0\end{array}$ & $\begin{array}{l}0 \\
0,0\end{array}$ & $\begin{array}{l}0 \\
0,0\end{array}$ & $\begin{array}{l}0 \\
0,0\end{array}$ & $\begin{array}{l}1 \\
0,9\end{array}$ & $\begin{array}{l}0 \\
0,0\end{array}$ & $\begin{array}{l}0 \\
0,0\end{array}$ & $\begin{array}{l}0 \\
0,0\end{array}$ & $\begin{array}{l}1 \\
0,43\end{array}$ \\
\hline \multicolumn{11}{|c|}{ Número de competencias en las que participó en el último año } \\
\hline $1-5$ & $\begin{array}{l}\mathrm{n} \\
\%\end{array}$ & $\begin{array}{l}15 \\
39,4\end{array}$ & $\begin{array}{l}19 \\
40,4\end{array}$ & $\begin{array}{l}21 \\
45,6\end{array}$ & $\begin{array}{l}55 \\
41,9\end{array}$ & $\begin{array}{l}38 \\
36,8\end{array}$ & $\begin{array}{l}40 \\
62,5\end{array}$ & $\begin{array}{l}22 \\
37,9\end{array}$ & $\begin{array}{l}1 \\
12,5\end{array}$ & $\begin{array}{l}101 \\
43,4\end{array}$ \\
\hline $6-10$ & $\begin{array}{l}\mathrm{n} \\
\%\end{array}$ & $\begin{array}{l}18 \\
47,3\end{array}$ & $\begin{array}{l}22 \\
46,8\end{array}$ & $\begin{array}{l}13 \\
28,2\end{array}$ & $\begin{array}{l}53 \\
40,4\end{array}$ & $\begin{array}{l}44 \\
42,7\end{array}$ & $\begin{array}{l}15 \\
23,4\end{array}$ & $\begin{array}{l}26 \\
44,8\end{array}$ & $\begin{array}{l}6 \\
75,0\end{array}$ & $\begin{array}{l}91 \\
39,1\end{array}$ \\
\hline $11-15$ & $\begin{array}{l}\mathrm{n} \\
\%\end{array}$ & $\begin{array}{l}3 \\
7,8\end{array}$ & $\begin{array}{l}3 \\
6,3\end{array}$ & $\begin{array}{l}9 \\
19,5\end{array}$ & $\begin{array}{l}15 \\
11,4\end{array}$ & $\begin{array}{l}11 \\
10,6\end{array}$ & $\begin{array}{l}7 \\
10,9\end{array}$ & $\begin{array}{l}6 \\
10,3\end{array}$ & $\begin{array}{l}0 \\
0,0\end{array}$ & $\begin{array}{l}24 \\
10,3\end{array}$ \\
\hline $16-20$ & $\begin{array}{l}\mathrm{n} \\
\%\end{array}$ & $\begin{array}{l}0 \\
0,0\end{array}$ & $\begin{array}{l}1 \\
2,1\end{array}$ & $\begin{array}{l}0 \\
0,0\end{array}$ & $\begin{array}{l}1 \\
0,7\end{array}$ & $\begin{array}{l}4 \\
3,8 \\
\end{array}$ & $\begin{array}{l}1 \\
1,5\end{array}$ & $\begin{array}{l}1 \\
1,7\end{array}$ & $\begin{array}{l}1 \\
12,5\end{array}$ & $\begin{array}{l}7 \\
3 \\
\end{array}$ \\
\hline $25-40$ & $\begin{array}{l}\mathrm{n} \\
\%\end{array}$ & $\begin{array}{l}0 \\
0,0\end{array}$ & $\begin{array}{l}0 \\
0,0\end{array}$ & $\begin{array}{l}2 \\
4,3\end{array}$ & $\begin{array}{l}2 \\
1,5\end{array}$ & $\begin{array}{l}2 \\
1,9\end{array}$ & $\begin{array}{l}1 \\
1,5\end{array}$ & $\begin{array}{l}0 \\
0,0\end{array}$ & $\begin{array}{l}0 \\
0,0\end{array}$ & $\begin{array}{l}3 \\
1,29\end{array}$ \\
\hline Ninguno & $\begin{array}{l}\mathrm{n} \\
\%\end{array}$ & $\begin{array}{l}0 \\
0,0\end{array}$ & $\begin{array}{l}1 \\
2,1\end{array}$ & $\begin{array}{l}1 \\
2,1\end{array}$ & $\begin{array}{l}2 \\
1,5\end{array}$ & $\begin{array}{l}1 \\
0,9\end{array}$ & $\begin{array}{l}0 \\
0,0\end{array}$ & $\begin{array}{l}1 \\
1,7\end{array}$ & $\begin{array}{l}0 \\
0,0\end{array}$ & $\begin{array}{l}2 \\
0,9\end{array}$ \\
\hline $\mathrm{N} / \mathrm{R}$ & $\begin{array}{l}\mathrm{n} \\
\%\end{array}$ & $\begin{array}{l}2 \\
5,2\end{array}$ & $\begin{array}{l}1 \\
2,1\end{array}$ & $\begin{array}{l}0 \\
0,0\end{array}$ & $\begin{array}{l}3 \\
2,2\end{array}$ & $\begin{array}{l}3 \\
2,9\end{array}$ & $\begin{array}{l}0 \\
0,0\end{array}$ & $\begin{array}{l}2 \\
3,4\end{array}$ & $\begin{array}{l}0 \\
0,0\end{array}$ & $\begin{array}{l}5 \\
2,15\end{array}$ \\
\hline Total & $\begin{array}{l}\mathrm{n} \\
\%\end{array}$ & $\begin{array}{l}38 \\
100\end{array}$ & $\begin{array}{l}47 \\
100\end{array}$ & $\begin{array}{l}46 \\
100\end{array}$ & $\begin{array}{l}131 \\
100\end{array}$ & $\begin{array}{l}103 \\
100\end{array}$ & $\begin{array}{l}64 \\
100\end{array}$ & $\begin{array}{l}58 \\
100\end{array}$ & $\begin{array}{l}8 \\
100\end{array}$ & $\begin{array}{l}233 \\
100\end{array}$ \\
\hline
\end{tabular}


Los escolares participantes han tenido una buena experiencia, tanto en competencias nacionales como internacionales, se destacan en el deporte del atletismo $30,38 \%$ a nivel mundial y un $50,48 \%$ a nivel centroamericano. En los deportes de combate se puede hacer mención de un $34,37 \%$ y $32,81 \%$ a nivel panamericano y centroamericano, respectivamente. Así, también podemos ver que en los deportes de pelota la experiencia la tienen a nivel centroamericano con un 51,72 \% y con un porcentaje similar en los deportes de rueda de un $50 \%$.

Hahn (1988) y Matveev (1991) afirman que comenzar tempranamente motiva los clubes, federaciones y a entrenadores a iniciar el proceso de entrenamiento tempranamente dirigido al alto rendimiento $\mathrm{y}$, cada vez más, a entrenar niños y niñas en búsqueda del éxito a cualquier precio prematuramente. Estudios (Martin et al., 2004) muestran la dinámica de los resultados de los mejores velocistas del mundo que comenzaron a competir a nivel nacional a los 13-14 años con resultados de 10,05 (s), que su mejor marca a nivel internacional a los 17-18 años fue de 10,10 (s) y que entrenaron y compitieron nueve años antes de esta edad para alcanzar estos resultados y mantenerlos hasta los 27,8 años.
Para cumplir con su función específica en el entrenamiento infantil y juvenil, las competiciones deben ser diferentes en cuanto a objetivos, tareas y contenidos, con una especialización creciente para el posterior desarrollo de la capacidad de rendimiento deportivo individual (Manno, 1994; Martin et al., 2004). En los últimos años, especialmente en las competencias de los jóvenes se ha presentado un incremento sustancial por la ampliación de las ofertas en las disciplinas deportivas, la diversificación de los programas de competición de las asociaciones, aumento del grado de organización de los sistemas de competencia específicos de la disciplina deportiva y finalmente el claro descenso de la edad de incorporación al deporte competitivo.

\section{Agentes socializadores en la iniciación de la práctica deportiva}

Los agentes socializadores en la iniciación deportiva son factores que parecen señalar el curso de la trayectoria deportiva. Un análisis más detallado sobre estas variables está tratado en el trabajo previo de Aguirre-Loaiza, Ayala y Ramos (2014); en cuanto a esta variable, se preguntó por cuál agente socializador ejercía influencia en la iniciación deportiva. Los resultados se describen en la tabla 7.

Tabla 7. Frecuencia y porcentaje de los principales agentes socializadores en la iniciación deportiva, según posición final (medallas) y grupos de deportes

\begin{tabular}{|c|c|c|c|c|c|c|c|c|c|c|}
\hline \multirow{2}{*}{ Variable } & & \multicolumn{4}{|c|}{ Medallas } & \multicolumn{4}{|c|}{ Grupo de deportes } & \multirow{2}{*}{ Total } \\
\hline & & Oro & Plata & Bronce & Total & Atlético & Combate & Pelota & Rueda & \\
\hline \multicolumn{11}{|l|}{ Agente socializador } \\
\hline Padre & $\begin{array}{l}\mathrm{n} \\
\%\end{array}$ & $\begin{array}{l}18 \\
31,0\end{array}$ & $\begin{array}{l}18 \\
29,5\end{array}$ & $\begin{array}{l}12 \\
20,3 \\
\end{array}$ & $\begin{array}{l}48 \\
26,9 \\
\end{array}$ & $\begin{array}{l}32 \\
22,5 \\
\end{array}$ & $\begin{array}{l}23 \\
25,5 \\
\end{array}$ & $\begin{array}{l}19 \\
23,7\end{array}$ & $\begin{array}{l}5 \\
41,6 \\
\end{array}$ & $\begin{array}{l}79 \\
24,4 \\
\end{array}$ \\
\hline Madre & $\begin{array}{l}\mathrm{n} \\
\% \\
\end{array}$ & $\begin{array}{l}15 \\
25,8\end{array}$ & $\begin{array}{l}17 \\
27,8\end{array}$ & $\begin{array}{l}14 \\
23,7 \\
\end{array}$ & $\begin{array}{l}46 \\
25,8 \\
\end{array}$ & $\begin{array}{l}37 \\
25,0 \\
\end{array}$ & $\begin{array}{l}20 \\
22,2 \\
\end{array}$ & $\begin{array}{l}22 \\
27,5\end{array}$ & $\begin{array}{l}3 \\
25,0\end{array}$ & $\begin{array}{l}82 \\
25,3\end{array}$ \\
\hline Otro familiar & $\begin{array}{l}\mathrm{n} \\
\%\end{array}$ & $\begin{array}{l}5 \\
8,6 \\
\end{array}$ & $\begin{array}{l}3 \\
4,9\end{array}$ & $\begin{array}{l}3 \\
5,0\end{array}$ & $\begin{array}{l}11 \\
6,1\end{array}$ & $\begin{array}{l}10 \\
7,0\end{array}$ & $\begin{array}{l}7 \\
7,7\end{array}$ & $\begin{array}{l}3 \\
3,7\end{array}$ & $\begin{array}{l}2 \\
16,6\end{array}$ & $\begin{array}{l}22 \\
6,8\end{array}$ \\
\hline Prof. E.F. & $\begin{array}{l}\mathrm{n} \\
\%\end{array}$ & $\begin{array}{l}4 \\
6,8\end{array}$ & $\begin{array}{l}1 \\
1,6\end{array}$ & $\begin{array}{l}6 \\
10,1\end{array}$ & $\begin{array}{l}11 \\
6,1\end{array}$ & $\begin{array}{l}13 \\
9,1\end{array}$ & $\begin{array}{l}3 \\
3,3\end{array}$ & $\begin{array}{l}6 \\
7,5\end{array}$ & $\begin{array}{l}0 \\
0,0\end{array}$ & $\begin{array}{l}22 \\
6,8\end{array}$ \\
\hline Entren. & $\begin{array}{l}\mathrm{n} \\
\% \\
\end{array}$ & $\begin{array}{l}6 \\
10,3 \\
\end{array}$ & $\begin{array}{l}3 \\
4,9 \\
\end{array}$ & $\begin{array}{l}7 \\
11,8 \\
\end{array}$ & $\begin{array}{l}16 \\
8,9 \\
\end{array}$ & $\begin{array}{l}21 \\
14,7 \\
\end{array}$ & $\begin{array}{l}11 \\
12,2 \\
\end{array}$ & $\begin{array}{l}7 \\
8,7\end{array}$ & $\begin{array}{l}0 \\
0,0\end{array}$ & $\begin{array}{l}39 \\
12\end{array}$ \\
\hline Amigo & $\begin{array}{l}\mathrm{n} \\
\%\end{array}$ & $\begin{array}{l}4 \\
6,8\end{array}$ & $\begin{array}{l}7 \\
11,4\end{array}$ & $\begin{array}{l}7 \\
11,8\end{array}$ & $\begin{array}{l}18 \\
10,1\end{array}$ & $\begin{array}{l}7 \\
4,9\end{array}$ & $\begin{array}{l}10 \\
11,1\end{array}$ & $\begin{array}{l}12 \\
15,0\end{array}$ & $\begin{array}{l}1 \\
8,3\end{array}$ & $\begin{array}{l}30 \\
9,3\end{array}$ \\
\hline Ini. propia & $\begin{array}{l}\mathrm{n} \\
\%\end{array}$ & $\begin{array}{l}6 \\
10,3\end{array}$ & $\begin{array}{l}8 \\
13,1\end{array}$ & $\begin{array}{l}7 \\
11,8\end{array}$ & $\begin{array}{l}21 \\
11,7\end{array}$ & $\begin{array}{l}13 \\
9,1\end{array}$ & $\begin{array}{l}15 \\
16,6\end{array}$ & $\begin{array}{l}7 \\
8,7\end{array}$ & $\begin{array}{l}1 \\
8,3\end{array}$ & $\begin{array}{l}36 \\
11,1\end{array}$ \\
\hline TV & $\begin{array}{l}\mathrm{n} \\
\% \\
\end{array}$ & $\begin{array}{l}0 \\
0,0 \\
\end{array}$ & $\begin{array}{l}2 \\
3,2 \\
\end{array}$ & $\begin{array}{l}1 \\
1,6 \\
\end{array}$ & $\begin{array}{l}3 \\
1,6 \\
\end{array}$ & $\begin{array}{l}2 \\
1,4 \\
\end{array}$ & $\begin{array}{l}0 \\
0,0 \\
\end{array}$ & $\begin{array}{l}3 \\
3,7\end{array}$ & $\begin{array}{l}0 \\
0,0\end{array}$ & $\begin{array}{l}5 \\
1,5\end{array}$ \\
\hline $\mathrm{N} / \mathrm{R}$ & $\begin{array}{l}\mathrm{n} \\
\%\end{array}$ & $\begin{array}{l}0 \\
0,0\end{array}$ & $\begin{array}{l}2 \\
3,2\end{array}$ & $\begin{array}{l}2 \\
3,3\end{array}$ & $\begin{array}{l}4 \\
2,2\end{array}$ & $\begin{array}{l}7 \\
4,9\end{array}$ & $\begin{array}{l}1 \\
1,1\end{array}$ & $\begin{array}{l}1 \\
1,2\end{array}$ & $\begin{array}{l}0 \\
0,0\end{array}$ & $\begin{array}{l}9 \\
2,8\end{array}$ \\
\hline Total & $\begin{array}{l}\mathrm{n} \\
\%\end{array}$ & $\begin{array}{l}58 \\
100\end{array}$ & $\begin{array}{l}61 \\
100\end{array}$ & $\begin{array}{l}59 \\
100\end{array}$ & $\begin{array}{l}178 \\
100\end{array}$ & $\begin{array}{l}142 \\
100\end{array}$ & $\begin{array}{l}90 \\
100\end{array}$ & $\begin{array}{l}80 \\
100\end{array}$ & $\begin{array}{l}12 \\
100\end{array}$ & $\begin{array}{l}324 \\
100\end{array}$ \\
\hline
\end{tabular}


Los resultados identificaron a los padres de familia como los principales agentes socializadores y los más influyentes en la iniciación deportiva del proceso, pues son aquellos a quienes el $50 \%$ de los deportistas reconoce como más influyentes en la iniciación deportiva, bien sea de manera individual o asociados a otros agentes socializadores. Así mismo, se encontró que el 25,5\% de los deportistas plantean que existe una interacción entre dos o más agentes socializadores, es decir, convergen no solo padres de familia, sino otros como el profesor de educación física.

En este mismo orden, los datos señalan que la figura paterna es la que mayor frecuencia presenta en la influencia al inicio de la práctica deportiva en comparación con la madre, aunque es importante tener en cuenta que la figura materna es el agente socializador más destacado en los niños de 9 y 11 años de edad (Bois et al., 2005); sin embargo, el efecto de madre o padre como modelos de conducta del niño en las prácticas deportivas puede variar en función de la disciplina deportiva. En contraste, los aportes de Torregrosa et al. (2007) han indicado que la práctica deportiva de los jóvenes futbolistas corresponde a los padres. En cuanto a los deportistas evaluados que obtuvieron los primeros puestos en la tabla de medallería, la mayor frecuencia correspondió a los padres de familia. Los anteriores datos concuerdan con los resultados pioneros en la década de los setenta (Greendorfer, 1977; Greendorfer y Lewko, 1978; Snyder y Spreitzer, 1973), y la evidencia actual sigue respaldando tales resultados con matices en los que la participación de los padres afecta la práctica deportiva (Bois et al., 2005; Fredricks y Eccles, 2005), por lo cual se ha señalado la importancia de programas de capacitación y formación de padres de deportistas.

Frente a otros agentes socializadores, como el entrenador, se evidenció que son un agente de referencia por parte de los deportistas. Sobre el entrenador recaen algunas responsabilidades que son compartidas con los padres de familia, $\mathrm{y}$ al igual que se ha mencionado la necesidad de capacitación y formación a los padres en la función acompañadora y orientadora, para los entrenadores igualmente es necesario este tipo de programas (Sousa, Cruz, Torregrosa, Vilches y Viladrich, 2006).

\section{CONCLUSIONES}

De acuerdo a lo comentado es importante enlistar algunas conclusiones: (I) la formación deportiva en la muestra evaluada es asumida especialmente por los entes deportivos no escolarizados. (II) La edad de inicio coincide con el promedio general recomendado por la literatura, aunque mayoritariamente lo hace en programas especializados, cuando debería hacerlo en programas polideportivos. (III) La detección de talentos se hace a la mitad de la población y solo a 1 de cada 6 se le aplican pruebas de todos los factores. (IV) El control se hizo a cerca del $90 \%$ de la muestra y se concentró en las pruebas físicas y de habilidades deportivas (técnica) y relegó aspectos como las valoraciones médicas, psicológicas, y antropométricas. (v) La participación en competencias deportivas es alta en número y en nivel internacional. (VI) La motivación para el deporte proviene especialmente de los padres y en este aspecto los puestos secundarios corresponden al entrenador y al profesor de educación física.

\section{AGRADECIMIENTOS}

A la Vicerrectoría de Investigaciones y Posgrados de la Universidad de Caldas. A los estudiantes del programa de Licenciatura en Educación Física y Deportes de la Universidad del Quindío que contribuyeron en la recolección de la información.

\section{REFERENCIAS}

Acosta, E. R. (2012). Iniciación y formación deportiva: Una reflexión siempre oportuna. Revista U.D.C.A. Actualidad \& Divulgación Científica, 15(Supl.), 57-65.

Aguirre-Loaiza, H. H., Ayala, C. F., y Ramos, S. (2014). Agentes socializadores en la iniciación deportiva en escolares de Centroamérica y el Caribe. Revista Latinoamericana de Estudios Educativos, 10(2), 62-80.

Aguirre-Loaiza, H. H., y Ramos, S. (2011). Ansiedad-estado $\mathrm{y}$ variables sociodemográficas en futbolistas juveniles colombianos durante competencia. Diversitas: Perspectivas en Psicología, 7(2), 239-251.

Aguirre-Loaiza, H. H., Ramos, S., y Agudelo, A. M. (2015). Motivación, grupo de deporte, nivel competitivo y edad deportiva en deportistas caldenses. Lúdica Pedagógica, 21(1), 141-151.

Alzate, D. A., Ayala, C. F., y Melo, l. G. (2012). Control del entrenamiento deportivo en Juegos Suramericanos 
Medellín 2010. Revista UDCA. Actualidad \& Divulgación Científica, 15 (Supl.), 87-96.

Arenas, J., y Aguirre-Loaiza, H. (2014). Ansiedad-estado a lo largo de las fases de competencia deportiva. Lúdica Pedagógica, 19(1), 111-121.

Blázquez, D. (1999). La iniciación deportiva y el deporte escolar (5..$^{\mathrm{a}}$ ed). Barcelona: INDE.

Bois, J. E., Sarrazin, P. G., Brustad, R. J., Trouilloud, D. O., y Cury, F. (2005). Elementary school children's perceived competence and physical activity involvement: the influence of parents' role model ling behaviours and perceptions of their child's competence. Psychology of Sport and Exercise, 6(4), 381-397.

Capetillo, R. (2011). Factores sociales que influyen en la formación deportiva de adolescentes. Lúdica Pedagógica, 2(16), 39-48.

Dias, R. G., Pereira, A. C., Negrão, C. E., y Krieger, J. E. (2007). Polimorfismos genéticos determinantes da performance física em atletas de elite. Revista Brasileira de medicina do Esporte, 13(3), 209-216.

Durand, M. (1988). El niño y el deporte. Barcelona: PaidósM.E.C.

Fernández, J., Vila, M. H., y Rodríguez, F. A. (2004). Modelo de estudio de la estructura condicional a través de un análisis multivariante enfocado a la detección de talentos en jugadores de Balonmano. Motricidad, 12, 169-185.

Fraile, A., Álamo J. M., Van der Bergh, K., González, J., Graca, A., Kirk, D. (2004). El deporte escolar en el siglo XXI: análisis y debate desde una perspectiva europea. Barcelona: Graó.

Fredricks, J. A., y Eccles, J. S. (2005). Family, socialization, gender, and sport motivation and involvement. Journal of Sport \& Exercise Psychology, 27(1), 3-31.

García, J., Navarro, M., y Ruiz, J. (1996). Bases teóricas del entrenamiento deportivo. Principios y aplicaciones. Madrid: Gymnos.

Giménez, F. J., Abad, M. T., y Robles, J. (2010). El proceso de formación del jugador durante la etapa de iniciación deportiva. Apunts. Educación Física y Deportes, 99(1), 47-55.

Gómez, P. (2011). El entrenamiento deportivo en el siglo XXI. Jaén: Formación Alcalá.

González, S., García, L. M, Contreras, O., y Sánchez-Mora, D. (2009). El concepto de iniciación deportiva en la actualidad. Retos: Nuevas tendencias en Educación Física, Deporte y Recreación, 15, 14-20.

González, G., Tabernero, B., y Márquez, S. (2000). Análisis de los motivos para participar en futbol y en tenis en la iniciación deportiva. Motricidad, 6, 47-66.
Greendorfer, S. L. (1977). Role of socializing agents in female sport involvement. Research Quarterly. American Alliance for Health, Physical Education and Recreation, 48 (2), 304-310.

Greendorfer, S. L., y Lewko, J. H. (1978). Role of family members in sport socialization of children. Research Quarterly. American Alliance for Health, Physical Education and Recreation, 49 (2), 146-152.

Hahn, E. (1988). Entrenamiento con niños. Barcelona: Martínez Roca.

Hernández, J. (2000). La iniciación a los deportes desde su estructura y dinámica: aplicaciones a la educación física escolar y al entrenamiento deportivo. Barcelona: Inde Publicaciones.

Hopkins, W. G. (2001). Genes and training for athletic performance. Sportscience, 5(1). Disponible en http:// naturalhuman.sportsci.org/jour/0102/jb.htm

Hoyos, L. A. (2012). Caracterización de los programas de deporte escolar en Bogotá. Análisis de los modelos didácticos empleados para su enseñanza (Tesis para optar al título de doctora en Ciencias de la Actividad Física y el Deporte). Universidad de León. León. España.

Issurin, V. (2012). Entrenamiento Deportivo. Periodización en bloques. Barcelona: Paidotribo.

Leiva J. H. (2010). Selección y orientación de talentos deportivos. Armenia: Kinesis-Universidad del Valle.

Manno, R. (1994). Fundamentos del entrenamiento deportivo. Barcelona: Paidotribo.

Matveev, L. (1991). Teoría y metodología de la cultura física. Moscú: Cultura física y deporte.

Martin, D., Nicolaus, J., Ostroswski, C., y Rost, K. (2004). Metodología del Entrenamiento Infantil y Juvenil. Barcelona: Paidotribo.

Melero, C., Vargas, M., y Pradas, F. (2005). Control biomédico del entrenamiento en tenis de mesa. Ejemplo de test de campo. Apunts: Educación Física y Deportes, 81, 67-76.

Melo, L., Moreno, H., y Aguirre, H. (2012). Métodos de entrenamiento de resistencia y fuerza empleados por los entrenadores para los Juegos Suramericanos, Medellín, Colombia, 2010. Revista U.D.C.A. Actualidad \& Divulgación Científica, 15(Supl.), 77-85.

Murcia N., Taborda, J., y Ángel, L. F. (2003). Escuelas de formación deportiva y entrenamiento deportivo infantil: un enfoque integral. Armenia: Kinesis.

Navarro, F. (2004). Entrenamiento adaptado a los jóvenes. Revista de Educación, 335, 61-80. 
Olmedilla, A., Ortega, E., Boladeras, E. J., Ortín F. J., y Bazaco, M. J. (2013). Entrenamiento en estrategias y técnicas psicológicas y percepción de ayuda en futbolistas juveniles. Sport TK. 2(1), 51-58.

Pahkhurst, A., Collins, D., y Macnamara, A. (2013). Talent development: linking the stakeholders to the process. Journal of Sports Sciences, 31(4), 370-380. doi: 10.1080/02640414.2012.733821

Pérez-Turpín, J., y Suárez, C. (2007). Estudio del abandono de los jóvenes en la competición deportiva. Journal of Human Sport and Exercise, 2(1), 28-34.

Platonov, V. N. (1999). El entrenamiento deportivo: teoría y metodología (6. $\underline{\text { ed.). }}$. Barcelona: Paidotribo.

Ramos, S., y Taborda, J. (2001). Orientaciones para la planificación del entrenamiento con niños. Apunts, 65(3), 45-52.

Sáenz-López, P. (2010). El proceso de formación del jugador. Wanceulen E.F. digital, 7, 16-41.

Serguienko, L. P. (2004). Genética del talento motor. Fundamentos de genética deportiva. Kiev: Escuela Superior de Cultura Física.

Sousa, C., Cruz, J., Torregrosa, M., Vilches, D., y Viladrich, C. (2006). Evaluación conductual y programa de asesoramiento personalizado a entrenadores (PAPE) de deportistas jóvenes. Revista de Psicología del Deporte, 15(2), 263-278.
Snyder, E. E., y Spreitzer, E. A. (1973). Family influence and involvement in sports. Research Quarterly. American Association for Health, Physical Education and Recreation, 44(3), 249-255.

Tabernero, B., Márquez, S., y Llanos, C. (2001). Elementos a analizar en el proceso de iniciación deportiva. Retos: Nuevas Tendencias en Educación Física, Deporte y Recreación (1), 9-15.

Torregrosa, M.; Cruz, J.; SousaI, C.; Viladrich, C.; Villamarín, F.; Garcia-Mas, A.; Palou, P. (2007). La influencia de padres y madres en el compromiso deportivo de futbolistas jóvenes. Rev. Latinoam. Psicol. 39,(2), 227 237.

Vásquez, B., Camerino, O., González, M., Del Villar F., Devis, J., y Sosa, P. (2001). Bases Educativas de la Actividad Física y el Deporte. Madrid: Síntesis S.A.

Weineck, J. (2005). Entrenamiento total. Barcelona: Paidotribo.

Werkiani, M. E., Zakizadeh, B., Golsefidi, F. N., y Rahimi, M. (2012). Review of the effective talent identification factors of badminton for better teaching to success. Procedia-Social and Behavioral Sciences, 31, 834-836. 
